\title{
Martian cave air-movement via Helmholtz resonance
}

\author{
Kaj E. Williams ${ }^{1 *}$, Timothy N. Titus ${ }^{1}$, Chris H. Okubo ${ }^{2}$, and Glen E. Cushing ${ }^{1}$ \\ ${ }^{1}$ Astrogeology Team, U.S. Geological Survey, Flagstaff, Arizona. USA \\ ${ }^{2}$ U.S. Geological Survey, Tucson, Arizona, USA
}

\begin{abstract}
Infrasonic resonance has previously been measured in terrestrial caves by other researchers, where Helmholtz resonance has been suggested as the plausible mechanism resulting in periodic wind reversals within cave entrances. We extend this reasoning to possible Martian caves, where we examine the characteristics of four atypical pit craters (APCs) on Tharsis, suggested as candidate cave entrance locations. The results show that, for several possible cave air movement periods, we are able to infer the approximate cave volumes. The utility of inferring cave volumes for planetary cave exploration is discussed.
\end{abstract}

Keywords: $\quad$ caves, resonance, Mars, wind, cave volume

Received 27 April 2017; Revised 29 September 2017; Accepted 29 September 2017

\begin{abstract}
Citation: Williams K.E., Titus T.N., Okubo C.H. and Cushing G.E., 2017. Martian cave air-movement via Helmholtz resonance. International Journal of Speleology, 46 (3), 439-444. Tampa, FL (USA) ISSN 0392-6672 https://doi.org/10.5038/1827-806X.46.3.2130
\end{abstract}

\section{INTRODUCTION AND BACKGROUND}

Caves may be broadly defined as natural airfilled cavities beneath the planetary surface that are connected to the atmosphere. Terrestrial caves are common on every continent and have multiple viable formation mechanisms. On Mars, caves have been hypothesized to exist as well (Carr et al., 1977; Boston, 2004; Wynne et al., 2008; Williams et al., 2010; Cushing, 2012). Martian cave formation processes are hypothesized to include mass-wasting (e.g., undercutting of scarps), soluble rock dissolution, tectonism and volcanic processes (e.g., lava tubes). The research of Cushing et al. (2007a,b, 2012, 2015) and others indicates that Martian caves exist in the form of lava tubes as well as drained basaltic dikes. The presence of extensive volcanic provinces suggests that lava tubes and dikes may be relatively common. Fig. 1 shows the two most noteworthy volcanic provinces: Elysium Montes and Tharsis Montes and the approximate locations of several pit craters identified by Cushing et al. (2015).

Air movement within caves is one of the most important mechanisms for moving scalars such as temperature and water vapor throughout a cave, given that advection and turbulent mixing timescales are typically much shorter than diffusive timescales. Terrestrial cave-air movement may be classified according to both the physical cave configuration as well as the driving forces involved. The physical cave configuration of interest in this study is a subterranean room connected to the atmosphere via a short passageway, as shown in Fig. 2.

One terrestrial air-movement mechanism occurs when small pressure differences between the cave interior and the external atmosphere produce a type of Helmholtz resonance (Cigna, 1968; Plummer, 1969; Faimon et al., 2012). Note that such resonances are not to be confused with passing weather systems creating pressure gradients, a type of pressure forcing referred to hereafter as "synoptic". Nor are the pressure gradients discussed here to be confused with $\mathrm{s} 1$ or s2 solar tides, which are yet another mechanism for cave winds. Rather, the Helmholtz resonance is a natural consequence of wind moving past the entrance of a cavity. Depending on the cave main chamber and passageway dimensions, infrasonic pressure oscillations occur in the range of $\sim 0.01 \mathrm{~Hz}$ to $1 \mathrm{~Hz}$. The equations governing the resonance are as follows.

The bulk modulus of any compressible substance, in this case air, is defined as

$$
\mathrm{K}=-\mathrm{V} \frac{\mathrm{dP}}{\mathrm{dV}} \approx-\mathrm{V} \frac{\Delta \mathrm{P}}{\Delta \mathrm{V}}
$$

where in this case $\mathrm{V}$ is the cave volume and $\mathrm{P}$ is the internal pressure. Consider a piston of air within the passageway in Fig. 2. We can then approximate a pressure difference as the passageway cross-sectional area A moves along a small distance y:

$$
\mathrm{K}=-\mathrm{V} \frac{\Delta \mathrm{P}}{\Delta \mathrm{V}} \Rightarrow \Delta \mathrm{P}=-\frac{\mathrm{KAy}}{\mathrm{V}}
$$



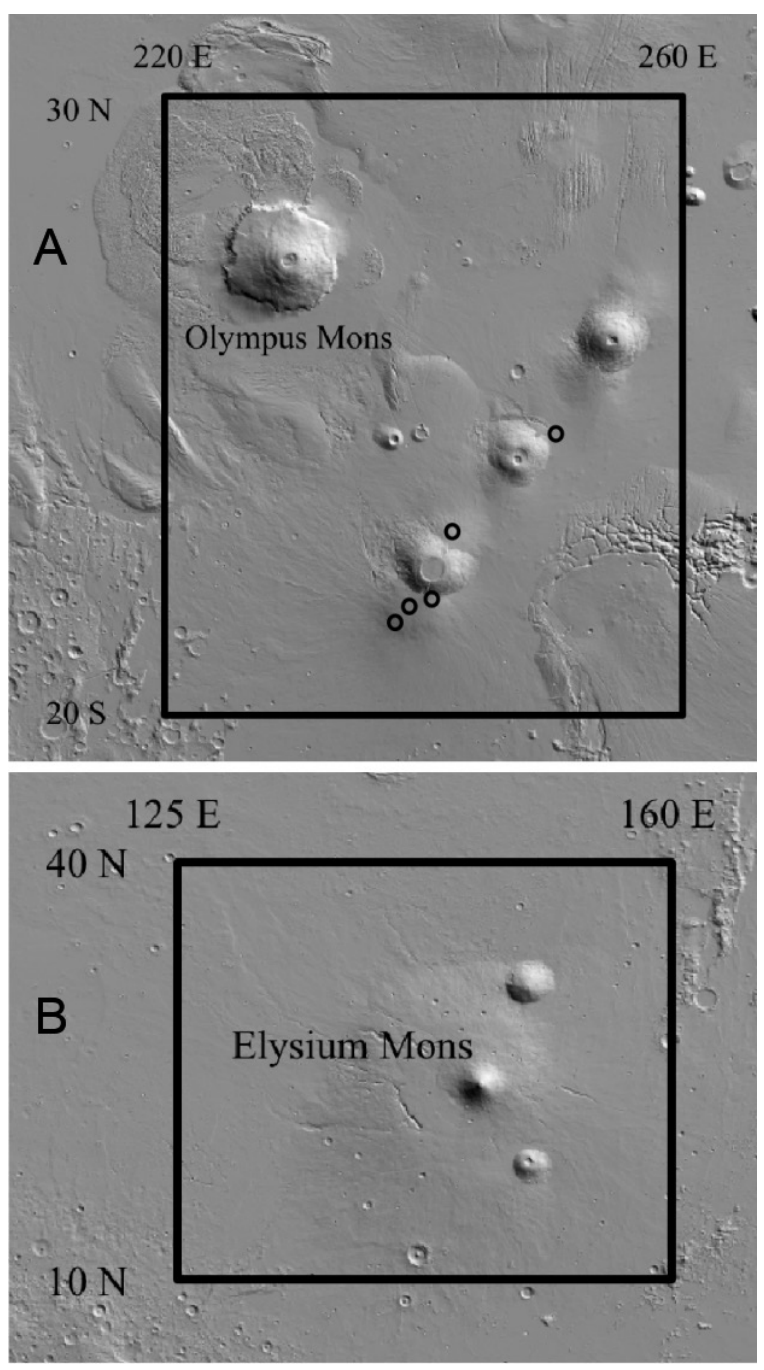

Fig. 1. MOLA shaded relief showing the approximate locations of A) Tharsis Montes and B) Elysium Montes. The locations of several pit craters, as identified by Cushing et al. (2015), are indicated by black circles in panel A.
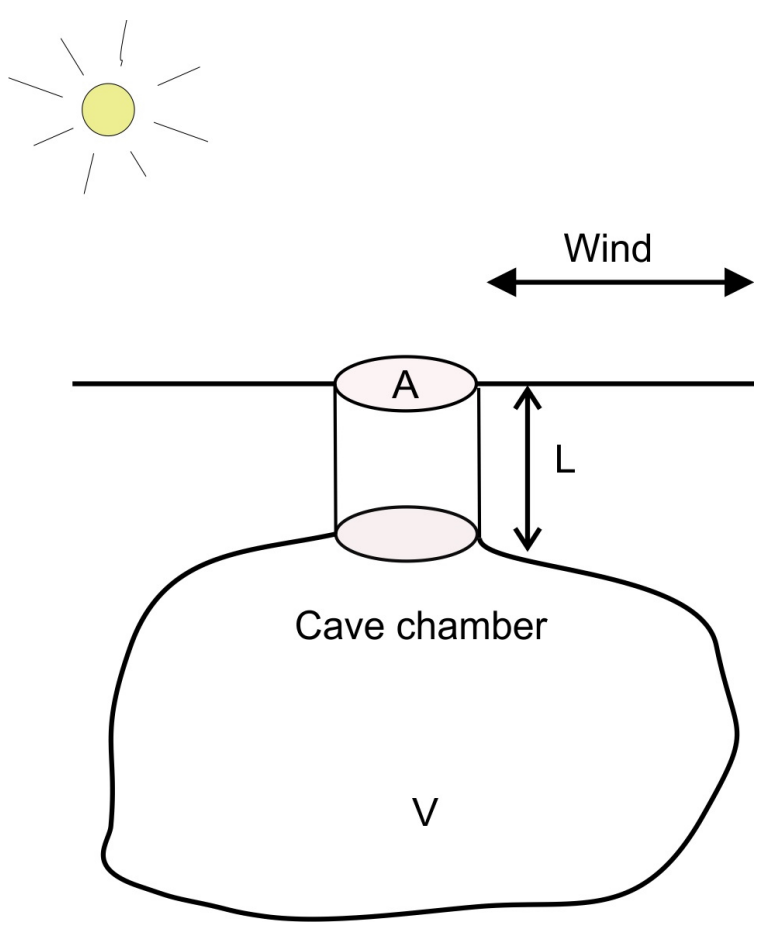

Fig. 2. Model configuration for this study: a subterranean chamber with a short connection to the atmosphere. Passage length is denoted $\mathrm{L}$, and passage cross-sectional area is denoted A. Volume (V) applies to the air within the cave chamber.
The force on the piston is then

$$
\mathrm{A} \Delta \mathrm{P}=-\frac{\mathrm{KA}^{2} \mathrm{y}}{\mathrm{V}}
$$

Let the air density be $\rho$. Then the air mass within the passageway is $A L \rho$. A simple force balance is then

$$
\operatorname{AL} \rho \frac{\mathrm{d}^{2} \mathrm{y}}{\mathrm{dt}^{2}}=-\frac{\mathrm{KA}^{2} \mathrm{y}}{\mathrm{V}} \Rightarrow \frac{\mathrm{d}^{2} \mathrm{y}}{\mathrm{dt}^{2}}+\frac{\mathrm{KA}}{\mathrm{VL} \rho} \mathrm{y}=0
$$

The solution of which is periodic, where the period can be expressed as

$$
\omega=\frac{2 \Pi}{\sqrt{\frac{\mathrm{KA}}{\mathrm{VL} \rho}}}
$$

The frequency is then

$$
f=\frac{u_{\text {sound }}}{2 \Pi} \sqrt{\frac{A}{V L}}
$$

Note that

$$
u_{\text {sound }}=\sqrt{\frac{K}{\rho}}
$$

is the speed of sound in a gas.

The above derivation may be modified to account for air flow resistance within the passageway. The additional turbulent drag term may be incorporated within the equation as

$$
\frac{\mathrm{d}^{2} \mathrm{y}}{\mathrm{dt}^{2}}+\frac{\mathrm{C}_{\mathrm{D}}}{1}\left(\frac{\mathrm{dy}}{\mathrm{dt}}\right)^{2}+\frac{\mathrm{KA}}{\mathrm{VL} \rho} \mathrm{y}=0
$$

where $l$ is a boundary layer length scale. The turbulent drag coefficient term $\frac{C_{D}}{l}$ is typically small ( 0.005) depending on the physical setting. For example, for atmospheric thermals, values of $\mathrm{Cd}=5$ and $1=1000 \mathrm{~m}$ are typically used (Stull, 2015). For flat smooth plates under fully turbulent flow parallel to the plate, $\mathrm{Cd} / 1=0.005$ is commonly used (e.g., Kundu $\&$ Cohen, 2004).

Plummer (1969) analyzed three terrestrial cave configurations in order to detect Helmholtz resonances. His simplest cave configuration was a cavity of roughly $140,000 \mathrm{~m}^{3}$ connected to the outside via a $360 \mathrm{~m}$ passageway. The power spectrum of the periodicallyreversing winds measxured in the passageway indicated a period of $\sim 2$ minutes. Plummer also analyzed a cave which he characterized as a double resonator, where two cavities were connected with a short passageway. Plummer's research also included a complex cave, the aptly-named "Breathing Cave" of Burnsville, Va. He found that the complexity of Breathing Cave created numerous resonant modes. In all three cases, he could detect periodic wind reversals within various cave passageways that were not attributable to synoptic forcing.

Faimon et al. (2012) also analyzed periodic winds in a complex cave with at least two entrances. Though their cave was much more complex than the caves we model in the present study, they could discern wind reversals with periods of seconds to minutes, which they attributed to Helmholtz-type resonances.

In the present study, we consider the simplest cave geometry possible, corresponding to the first 
of Plummer's three caves: a single entrance to a single void. Consideration of more complicated cave geometries would require additional mathematical complexity.

Fig. 3 shows two solutions of Eq. 3 for an initial condition of $\mathrm{y}(0)=0$ and $\mathrm{y}^{\prime}(0)=1$, passageway area $\mathrm{A}=5 \mathrm{~m}^{2}$, length $\mathrm{L}=10 \mathrm{~m}$ and cave volume $\mathrm{V}=10^{5} \mathrm{~m}^{3}$. Earth atmospheric pressure of $1013.25 \mathrm{mb}$ and Mars pressure of $6.11 \mathrm{mb}$ were used as well as a temperature of $273 \mathrm{~K}$. In addition, the appropriate bulk modulus and atmospheric density for each planet was used. For identical cave dimensions, the cave wind oscillation periods vary slightly between Earth and Mars, where periods are approximately 8 and 12 s., respectively. The magnitude of the cave winds is related to the magnitude of the excitation (surface) winds.

Note that in the governing Equations 1-3 there is absolutely nothing specifically requiring a terrestrial atmosphere. It suffices to have any planetary atmosphere in which the atmosphere in the surface layer behaves approximately like an ideal gas. There are, of course, differences in the parameters of Eq. 1-3 depending on the planetary atmosphere in question. The Martian atmosphere has a much lower density than earth (Mars $\sim 0.012 \mathrm{~kg} / \mathrm{m}^{3}$ vs. Earth $\sim 1.2 \mathrm{~kg} / \mathrm{m}^{3}$ ) and the bulk modulus $\mathrm{K}$ (Mars $\sim 7.8 \times 10^{3}$ vs. Earth $\left.\sim 1.4 \times 10^{5}\right)$. As shown above, the speed of sound $\mathrm{u}_{\text {sound }}$ combines both atmospheric density and bulk modulus. Hence Eq. 2 indicates that, for similar cave dimensions, the resonance period scales as the inverse of the speed of sound for the planet in question. For Mars, where the speed of sound is $\sim 259 \mathrm{~m} / \mathrm{s}$ (for Earth, $\sim 331 \mathrm{~m} / \mathrm{s}$ ) we would therefore expect the resonance period to be longer than the Earth case for the same cave (Fig. 3).

If passage area $\mathrm{A}$, length $\mathrm{L}$, atmospheric bulk modulus and density for the atmosphere frequency of wind reversals for a cave entrance are known, then cave volume $\mathrm{V}$ may be inferred (Fig. 4). Note that the magnitude of both the excitation winds and the cave winds are irrelevant to the volume calculation; only the period is of interest.

\section{PHYSICAL SETTING AND APPLICATION}

The cave geometry considered in this study is that of a subterranean room connected to the atmosphere by a single shaft in the ceiling. Consideration of more complicated cave geometries, while certainly worthwhile, are beyond the scope of this preliminary study. An example of the type of simple configuration considered in this study is a horizontal lava tube with a collapsed ceiling, providing a single entrance to the cave, or a partially drained basaltic dike with a single skylight. Two Mars examples are shown in Fig. 5A. Such cave configurations are also not unusual on Earth. An example of such an entrance is shown in Fig. 5B, taken in Hawaii. It should be noted, however, that the Helmholtz resonance phenomenon discussed
A Earth - Modeling Cave Air Movement as Helmholtz Resonance

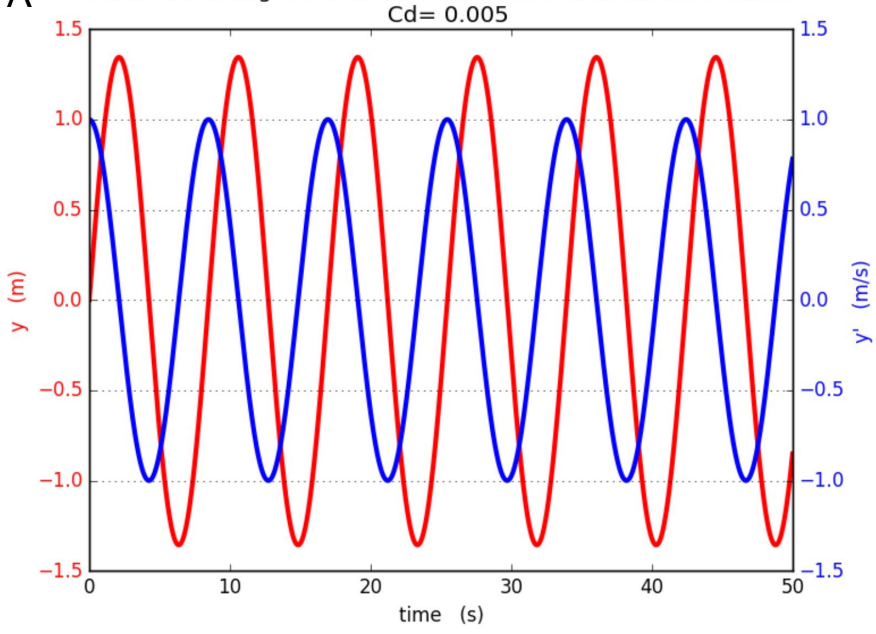

B Mars - Modeling Cave Air Movement as Helmholtz Resonance

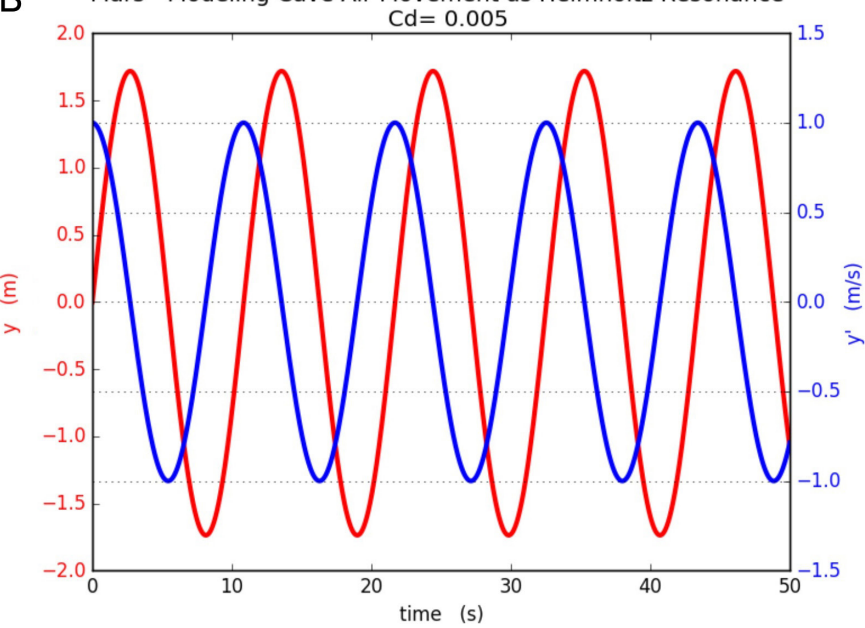

Fig. 3. Solutions of Eq. 3 for A) Earth and B) Mars. The period of the Mars cave air oscillation is approx. $50 \%$ longer than the Earth period.

Estimating Cave Air Volume as a Function of Resonance Period

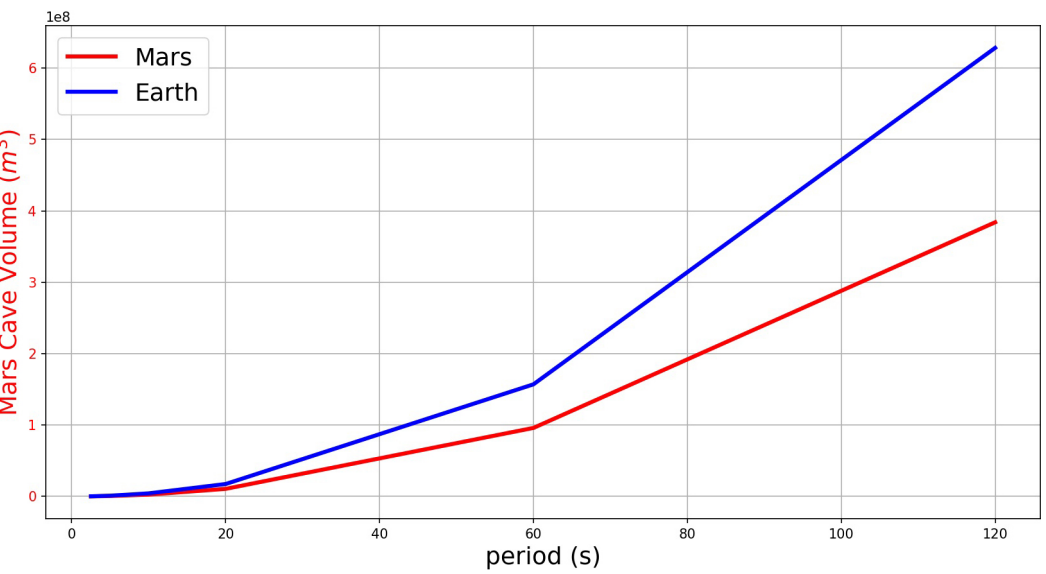

Fig. 4. Cave volume as a function of resonance period. For a given period, inferred Fig. 4 . Cave volume as a function of resonance
Earth cave volumes are $\sim 1.5 x$ Mars volumes.

in this study does not depend on the speleogenetic circumstances.

The Wood Valley pit crater and associated cave system is an example of the type of cave geometry considered in this study, though it is more complex than the idealized case we consider here. Wood Valley pit crater is located on the southeast rift zone of Kilauea volcano, Hawaii (Okubo \& Martel, 1998). The pit has a surface diameter of $\sim 30 \mathrm{~m}$, and a depth of $\sim 40 \mathrm{~m}$ (Okubo et al., 2015). The entrance to the associated cave is located at the base of the northeast 

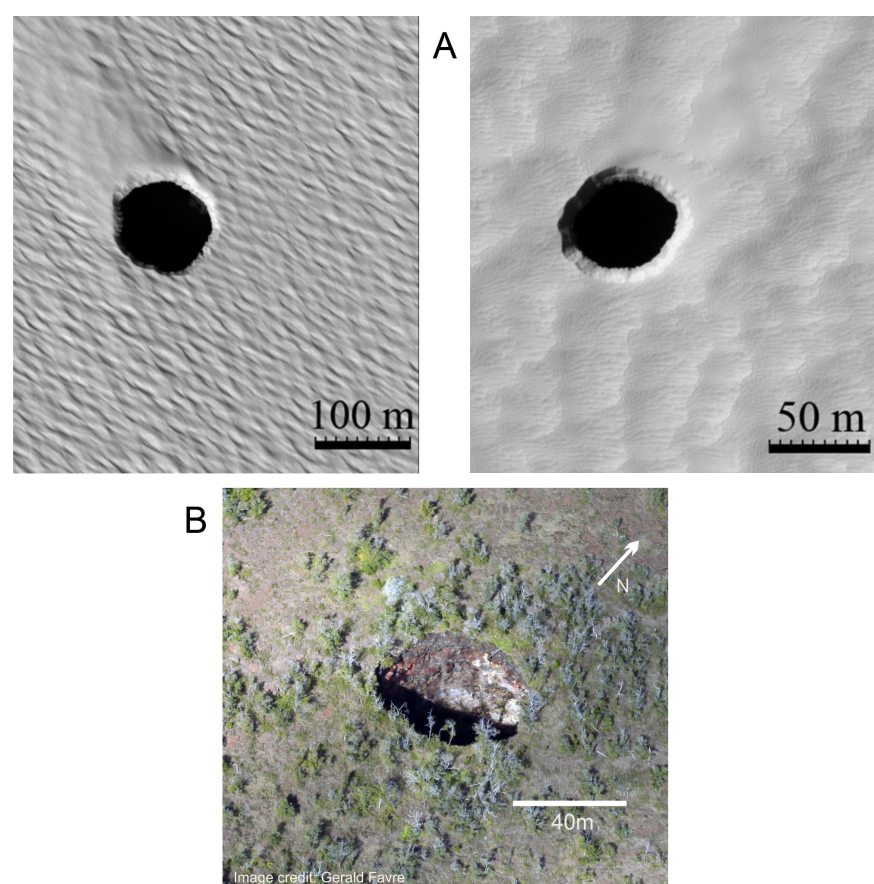

Fig. 5. A) Example of pit craters on Mars; B.) Example of terrestrial pit crater, in this case the Wood valley pit crater on the southeast rift zone of Kilauea Volcano, Hawaii. Wood Valley pit crater has been confirmed to be a skylight of a partially-drained basaltic dike (Okubo \& Martel, 1998) (image credit: Gerald Favre).

wall of the pit. The cave descends to a depth of $\sim 100 \mathrm{~m}$, where it leads to a quasi-linear and quasi-horizontal $\sim 580 \mathrm{~m}$-long passage (Favre, 2014).

Similar cave configurations are hypothesized to exist on Mars as well. The work of Cushing et al. (2015) and Cushing (2012) has identified numerous locations on both Elysium and Tharsis which appear to be collapsed lava tube ceilings. The results of such collapse structures resemble craters (Fig. 6, inset). Cushing et al. (2015) have measured the crater diameters and inferred the crater depths.

Using the work of Cushing et al. (2015), we have identified five examples of pit craters with large depth to
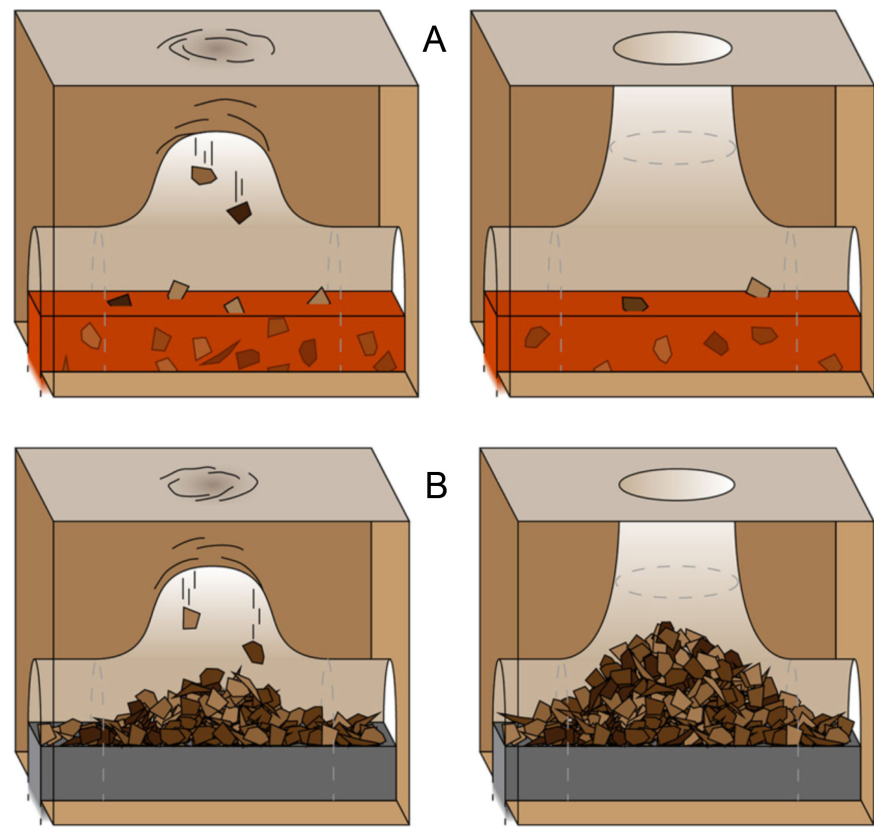

Fig. 6. Schematic showing suggested formation mechanism via the collapse of lava tube ceilings (Cushing et al., 2015). In A) the debris is transported away and in B) the debris accumulates at the base of the skylight. diameter $(\mathrm{d} / \mathrm{D})$ ratios. Using the measured passageway cross-sectional areas (crater diameters) and the inferred depths (L), we then use Eq. 2 to solve for the cave volume $\mathrm{V}$, given several candidate air movement periods. The results are summarized in Table 1.

As shown in Table 1, the inferred cave volumes range between $1.6 \times 10^{5}-4.7 \times 10^{7} \mathrm{~m}^{3}$, depending on the hypothetical periods $(\omega)$. The definition of terrestrial caves ordinarily includes the stipulation that the voids are large enough to accommodate humans. It should be noted, however, that the inferred cave volumes in Table 1 do not necessarily imply any particular cave void geometry; a small portion of the air volume could even be dispersed throughout fractured material, such as the rubble on the floor. The error associated with a $10 \%$ measurement error in entrance diameter results in a $22 \%$ error in inferred cave volume, whereas a $10 \%$ error in entrance depth results in only a $9 \%$ cave volume error. The fact that the dependent variable is less sensitive to the inferred depth is fortuitous given that the cave depth is expected to be slightly more difficult to ascertain than the entrance diameter.

\section{DISCUSSION AND CONCLUSION}

Our results show that cave volumes may be inferred for simple cave geometries by measuring air reversal periods. To measure cave air movement, it would be sufficient to install anemometers within the cave passageway. In order to obtain representative wind velocities, it would be desirable to install more than one anemometer within the passageway, close to the entrance (if the anemometer is too far in the cave, the signal might become overly damped or reduced beyond detectable limits). Such anemometers would need to be able to measure wind speeds of $<1 \mathrm{~m} / \mathrm{s}$. Given that the periodicity of the wind speeds is the most important consideration, Plummer (1969) used a small device on a tripod which measured the persistent wind direction (rather than wind speeds). Once the persistent wind direction reversed, the device recorded the time of reversal. Such devices would be relatively simple to construct and would most likely have very modest electrical current requirements, making them ideal for planetary missions.

The choice of precise location for the anemometer is difficult, given that the sensor should ideally be in a part of the cave passageway which has a constriction (so that the faster winds provide larger wind-reversal magnitudes), but is far away from the shearing turbulence (caused by the external driving wind) found at the cave entrance. As indicated in Fig. 7, the ideal placement of the anemometer depends on the cave geometry, but in general the anemometer should be placed in a restricted part of the entrance, but far enough into the cave in order to not be affected by external wind-flow entrance effects (typically at least several cave diameter lengths for pipe-flow). Placing the anemometer too close to the cave entrance would introduce too much noise (e.g., in the form of smallscale turbulence effects) from the horizontal shearing wind at the surface. The anemometer placement in Plummer (1969) was located in a constriction, 
Table 1. Inferred cave volumes, given four hypothetical cave air movement periods $(\omega)$. Note that a $10 \%$ variation of diameter or depth is included for crater APC003 to determine volume estimated sensitivity. For $\omega=20.0$ s a $10 \%$ error in the estimate of the entrance diameter results in approximately a $22 \%$ cave volume discrepancy, and a $10 \%$ error in depth estimate results in a $9 \%$ volume discrepancy.

\begin{tabular}{|c|c|c|c|c|c|c|c|c|}
\hline $\begin{array}{c}\text { Crater } \\
\text { designation } \\
\text { (from Cushing } \\
\text { et al., 2015) }\end{array}$ & $\begin{array}{c}\text { Latitude } \\
\qquad\left({ }^{\circ} \mathrm{N}\right)\end{array}$ & $\begin{array}{c}\text { Longitude } \\
\left({ }^{\circ} \mathrm{E}\right)\end{array}$ & $\begin{array}{l}\text { Diameter } \\
\text { (m) }\end{array}$ & Depth (m) & $\begin{array}{c}\text { Cave } \\
\text { Volume }\left(\mathrm{m}^{3}\right) \\
\omega=2.5 \mathrm{~s}\end{array}$ & $\begin{array}{c}\text { Cave } \\
\text { Volume }\left(\mathrm{m}^{3}\right) \\
\omega=5.0 \mathrm{~s}\end{array}$ & $\begin{array}{c}\text { Cave } \\
\text { Volume }\left(\mathrm{m}^{3}\right) \\
\omega=10.0 \mathrm{~s}\end{array}$ & $\begin{array}{c}\text { Cave } \\
\text { Volume }\left(\mathrm{m}^{3}\right) \\
\omega=20.0 \mathrm{~s}\end{array}$ \\
\hline APC018 & -13.86 & 236.76 & 60 & 85 & $3.53 \times 10^{5}$ & $1.41 \times 10^{6}$ & $5.65 \times 10^{6}$ & $2.26 \times 10^{7}$ \\
\hline $\mathrm{APC} 025$ & 4.137 & 250.107 & 60 & 88 & $3.41 \times 10^{5}$ & $1.36 \times 10^{6}$ & $5.45 \times 10^{6}$ & $2.18 \times 10^{7}$ \\
\hline APC003 & -12.473 & 237.696 & 30 & 47 & $1.60 \times 10^{5}$ & $6.38 \times 10^{5}$ & $2.55 \times 10^{6}$ & $1.02 \times 10^{7}$ \\
\hline APC003 & -12.473 & 237.696 & $\begin{array}{l}30 \\
+3\end{array}$ & 47 & $1.93 \times 10^{5}$ & - & - & $1.24 \times 10^{7}$ \\
\hline APC003 & -12.473 & 237.696 & 30 & $\begin{array}{c}47 \\
+4.7\end{array}$ & $1.45 \times 10^{5}$ & - & - & $0.93 \times 10^{7}$ \\
\hline APC075 & -5.533 & 241.393 & 160 & 293 & $7.28 \times 10^{5}$ & $2.91 \times 10^{6}$ & $1.16 \times 10^{7}$ & $4.66 \times 10^{7}$ \\
\hline $\mathrm{APC} 004$ & -11.571 & 239.935 & 30 & 45 & $1.67 \times 10^{5}$ & $6.67 \times 10^{5}$ & $2.67 \times 10^{6}$ & $1.07 \times 10^{7}$ \\
\hline
\end{tabular}

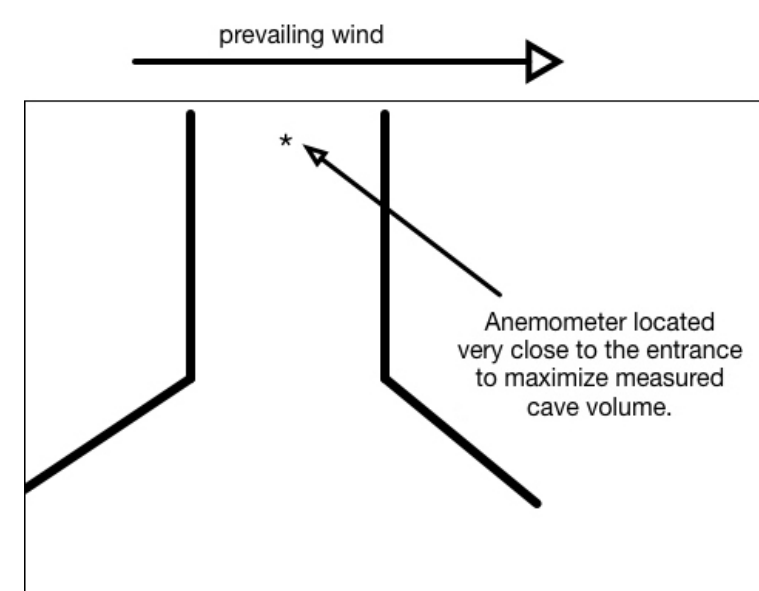

A. Idealized Case - sensor placement

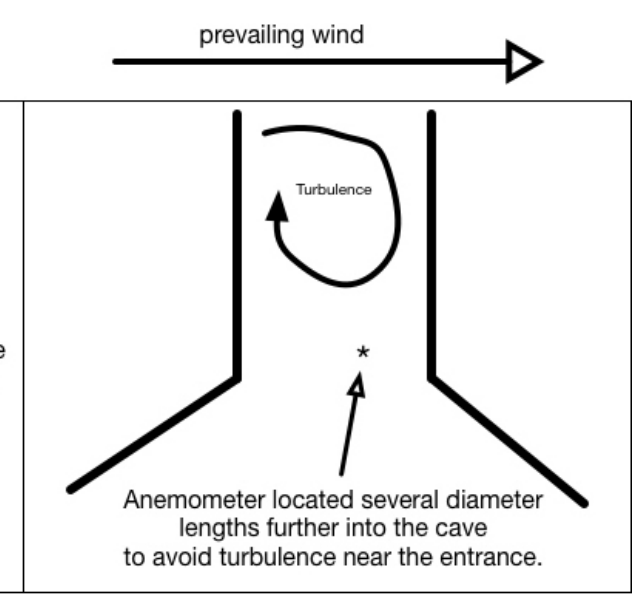

B. Realistic Case - sensor placement

Fig. 7. Diagram showing optimal sensor (anemometer) placement for measuring resonances. In A) we see an idealized case where no wind-shearing effects influence the resonance. In such a case, it would be optimal to place the sensor near/at the entrance in order to maximize the cave volume being measured. In B) we have a more realistic case, where wind-shearing or small-scale turbulence effects exist in the cave entrance and therefore the sensor placement should be moved further (several diameters) into the cave.

$\sim 35 \mathrm{~m}$ into the cave. His placement was most likely well beyond the range of turbulent entrance effects, and being in a constricted area provided maximal resonance signal.

The work of Faimon et al. (2012) and others has shown that the wind data from cave passages can contain a considerable amount of noise (e.g., higherfrequency signals). It may therefore be necessary to include anemometers with faster response times (such as ultrasonic or hot-wire anemometers). Such anemometers may have higher power requirements, further complicating their use for planetary missions. Their use may have implications for the accuracy of the measurements as well. Accuracy of the cave volume estimations would depend on two points: the accuracy of measurements of the wind reversal intervals (the period) and judicious filtering in order to increase the overall signal to noise ratio. If a bandpass filter could be applied to a given cave wind dataset, the window of cave wind periods would be applied to limits between 1 s to 10 minutes, reducing the noise considerably.

Another potential complication is that the main resonance mode of the cave will not be activated if the flow past the cave entrance is fully turbulent. If the wind speed is too high then the Reynolds number based on the length scale (entrance diameter) and external wind speeds will fall within the turbulent regime $(\sim$ >4000). This difficulty is not as severe as it seems, however, since wind speeds in general are highly variable and the resulting dataset may simply be filtered for external wind speeds less than the required threshold. The exact threshold would be determined for a particular cave entrance by estimating the passageway diameter (presumably done from orbit). Once the diameter is estimated, the maximum winds for a low-pass filter would be found for atmospheric viscosity $v$ and entrance diameter $D$ :

$$
\mathrm{u}<\frac{4000 v}{\mathrm{D}}
$$

In general, the characterization of caves from orbit is inherently difficult if not impossible. Imaging can be used to locate possible cave entrances but cannot image through overhangs and rocky overburden. Gravitational anomalies have been detected that may be associated with underground voids on the Moon (K. Mitchell, pers. comm., 2016; Sood et al., 2016). Ground Penetrating Radar is another promising approach which has not been deployed. The use of rovers to explore caves is necessary, but rovers have limited range for exploration. Site selection 
for these rovers becomes mission critical and new ways to estimate potential cave volumes become imperative. The use of Helmholtz resonance as a proxy for cave volume has the potential to estimate cave volumes with a minimal set of equipment, namely a simple anemometer located within the mouth of the cave. Orbital imaging or low altitude airplanes or balloons may provide the needed information to identify potential cave entrances. Once the low-atmosphere platforms have characterized potential skylights and pits, then rovers (equipped with anemometers) could provide estimation of cave volume prior to descent.

\section{REFERENCES}

Boston P.J., Frederick R.D., Welch S.M., Werker J., Meyer T.R., Sprungman B., Hildreth-Werker V. \& Thompson S.L., 2004a - Extraterrestrial subsurface technology test bed: Human use and scientific value of Martian caves. In: El-Genk M.S. \& Bragg M.J. (Eds.), Space technology and applications international forum-STAIF 2004: Conference on thermophysics in microgravity; commercial/civil next generation space transportation; $21^{\text {st }}$ Symposium on space, nuclear power and human space exploration; Space colonization; New frontiers $\&$ future concepts, Vol. 699, AIP, Albuquerque, New Mexico (USA), p. 1007-1018. https://doi.org/10.1063/1.1649667

Boston P.J., 2004b - Extraterrestrial caves. In: Gunn J. (Ed.), Encyclopedia of cave and karst science, London, Fitzroy-Dearborn Publishers, p. 355-358.

Carr M., Greeley R., Blasius K. \& Guest J., 1977 - Some Martian volcanic features as viewed from the Viking orbiters. Journal of Geophysical Research, 82: 39854015. https://doi.org/10.1029/JS082i028p03985

Cigna A.A., 1968 - An analytical study of air circulation in caves. International Journal of Speleology, 3 (1/2): 41-54. https://doi.org/10.5038/1827-806X.3.1.3

Cushing G.E., Titus T.N., Wynne J.J. \& Christensen P.R., 2007a - THEMIS observes possible cave skylights on Mars, Lunar and Planetary Science, 38, Abstract 1371. https://doi.org/10.1029/2007GL030709

Cushing G.E., Titus T.N., Wynne J.J. \& Christensen P.R., 2007b - THEMIS observes possible cave skylights on Mars, Geophysical Research Letters, 34: L17201. https://doi.org/10.1029/2007GL030709
Cushing G.E., 2012 - Candidate cave entrances on Mars. Journal of Cave and Karst Studies, 74 (1): 33-47. https://doi.org/10.4311/2010EX0167R

Cushing G.E., Okubo C.H. \& Titus T.N., 2015 - Atypical pit craters on Mars: New insights from THEMIS, CTX, and HiRISE observations, Journal of Geophysical Research - Planets, 120: 1023-1043. https://doi.org/10.1002/2014JE004735

Faimon J., Troppová D., Baldík V. \& Novotný R., 2012 Air circulation and its impact on microclimatic variables in the Cisarská Cave (Moravian Karst, Czech Republic). International Journal of Climatology, 32: 599-623. https://doi.org/10.1002/joc.2298

Favre G., 2014 - Volcanospéléologie à Hawaii: un pseudokarst très exotique. Stalactite, 64: 14-25.

Kundu P.K. \& Cohen I.M., 2004 - Fluid mechanics. ( $3^{\text {rd }}$ Ed.), Elsevier, 759 p.

Leveille R.J. \& Datta S., 2010 - Lava tubes and basaltic caves as astrobiological targets on Earth and Mars: A review, Planetary \& Space Science, 58: 592-598.

https://doi.org/10.1016/j.pss.2009.06.004

Okubo C.H. \& Martel S.J., 1998 - Pit crater formation on Kilauea volcano, Hawaii, Journal of Volcanology \& Geothermal Research, 86 (1-4): 1-18. https://doi.org/10.1016/S0377-0273(98)00070-5

Okubo C.H., Cushing G.E. \& Titus T.N., 2015 - Mapping the cave and dike structure below Wood Valley pit crater, Killauea Volcano, Hawai'I. In: $2^{\text {nd }}$ International Planetary Caves Conference, No. 1883, p. 9005.

Plummer W.T., 1969 - Infrasonic resonances in natural underground cavities. The Journal of the Acoustical Society of America, 46: 1074-1080. https://doi.org/10.1121/1.1911823

Sood R., Melosh H.J. \& Howell K., 2016 - Lunar advanced radar orbiter for subsurface sounding (LAROSS): Lava tube exploration mission. In: $26^{\text {th }}$ AAS/AIAA Space Flight Mechanics Meeting, Napa, CA., p. 158.

Stull R., 2015 - Practical meteorology: An algebra-based survey of atmospheric science, University of British Columbia, 938 p.

Williams K.E., McKay C.P., Toon O.B. \& Head J.W., 2010 - Do ice caves exist on Mars? Icarus, 209 (2): 358-368. https://doi.org/10.1016/j.icarus.2010.03.039

Wynne J.J., Titus T.N. \& Chongdiaz G., 2008 - On developing thermal cave detection techniques for earth, the moon and mars. Earth and Planetary Science Letters, 272: 240-250.

https://doi.org/10.1016/j.epsl.2008.04.037 